\title{
Hospital-Based Health Care Worker Perceptions of Personal Risk Related to COVID-19
}

\author{
Everett Chu, MD, Kyung-Min Lee, Ronnie Stotts, MD, Ivy Benjenk, RN, MPH, \\ Geoffrey Ho, MBBS, David Yamane, MD, Billy Mullins, DNP, RN, and \\ Eric R. Heinz, MD, PhD
}

Background: Health care workers treating Coronavirus disease 2019 (COVID-19) patients face significant stressors such as caring for critically ill and dying patients, physically demanding care requiring new degrees of personal protective equipment use, risk of contracting the disease, and putting loved ones at risk. This study investigates the stress impact from COVID-19 exposure and how nurses and medical providers (eg, physicians, nurse practitioners, physician assistants) experience these challenges differently.

Methods: An electronic, self-administered questionnaire was sent to all hospital staff over 6 weeks surveying exposure to COVID-19 patients and degree of stress caused by this exposure. Responses from medical providers and nurses were analyzed for significant contributors to stress levels, as well as comparing responses from medical providers versus nurses.

Results: Stress levels from increased risk of disease contraction while on the job, fear of transmitting it to family or friends, and the resulting social stigma were highest in medical staff during the COVID-19 pandemic. Compared with medical providers, nurses had nearly 4 times the odds of considering job resignation due to COVID-19. However, most health care workers $(77.4 \%$ of medical providers and $52.9 \%$ of nurses) strongly agreed or agreed with the statements indicating high levels of altruism in their desire to treat CoVID-19 patients.

Conclusion: The significant stress burden placed on nurses likely contributes to increased thoughts of job resignation. However, health care providers displayed high levels of altruism during this time of extreme crisis, despite their personal risks of caring for COVID-19 patients. ( $\mathrm{J}$ Am Board Fam Med 2021;34:S103-S112.)

Keywords: Altruism, COVID-19, Hospital Personnel, Occupational Stress, Pandemics, Surveys and Questionnaires, Workplace

\section{Introduction}

With many Americans at home, health care workers remain on the front lines during the Coronavirus disease 2019 (COVID-19) pandemic. As these health care workers confront various

This article was externally peer reviewed.

Submitted 5 July 2020; revised 27 October 2020; accepted 28 October 2020.

From the Department of Anesthesiology and Critical Care Medicine, George Washington School of Medicine \& Health Sciences, Washington, DC (EC, RS, IY, GH, IB, DY, ERH); George Washington School of Medicine and Health Sciences, Washington, DC (K-ML); Department of Emergency Medicine, George Washington School of Medicine and Health Sciences, Washington, DC (DY); School of Nursing, George Washington University, Washington, DC (BM).

Funding: The authors received no financial support for the research, authorship, and/or publication of this article.

Conflict of interest: To the best of our knowledge, the named authors have no conflict of interest, financial or otherwise. challenges accompanied by COVID-19, the potential impact on their stress levels and mental health is worrisome. A recent cross-sectional study in China showed that around $71 \%$ of health care workers were in distress and $50 \%$ were experiencing clinical symptoms of depression during the COVID-19 pandemic. ${ }^{1}$ Earlier studies from the Severe Acute Respiratory Syndrome (SARS-CoV1) pandemic found health care workers' perceptions of the risks that they were taking by working in health care during the pandemic were significantly positively associated with post-traumatic stress.,

Corresponding author: Everett Chu, MD, Department of Anesthesiology and Critical Care Medicine, 2300 M St, NW, 7th Floor, Washington, DC 20037, Telephone: 202715-4750, Fax: 202-715-4759 (E-mail: etchu@gwu.edu). 
Considering each disease outbreak poses its own unique set of perceived risks, it is crucial to identify those specifically precipitated by COVID $-19 .{ }^{4}$

Previous studies from the SARS-CoV-1 epidemic found that health care workers were stigmatized by their communities and did not receive support from their families and friends for working during the pandemic. ${ }^{3}$ Early work from China at the beginning of the COVID-19 pandemic identified similar patterns. ${ }^{5}$

At the same time, health care workers generally have been found to have higher levels of altruism than the general population. ${ }^{6}$ During the SARS$\mathrm{CoV}-1$ pandemic, many nurses volunteered to care on SARS units. ${ }^{7}$ Altruism had been found to be protective against post-traumatic stress during the SARS pandemic ${ }^{3}$, and may therefore be an important quality to monitor and encourage.

The objectives of this study were first to explore health care workers' perceptions of the risks that they are taking by working during the pandemic, and second, to investigate how different groups of health care workers perceive the risks of caring for patients during COVID-19.

\section{Methods}

\section{Setting}

From March 26, 2020 to May 9, 2020, hospital staff (clinical as well as non-clinical) were invited to participate in a self-administered survey at the George Washington University Hospital (GWUH), a 431bed, urban, quaternary care, academic teaching hospital. From March to May 2020, the GWUH cared for approximately 1000 COVID-19 patients. This study received an exemption from the George Washington Institutional Review Board (NCR202386).

\section{Survey Tool}

The survey was set up as a larger longitudinal study to track the perceptions of risk of all hospital staff as the pandemic progressed. The invitation was sent out electronically, and survey responses were recorded directly into REDCap (Vanderbilt University, Nashville, TN), a secure, HIPAA compliant, web-based database application.

The questionnaire (Appendix 1) consisted of 3 parts: basic demographic data including role and specialty in the hospital, nature of COVID-19 exposure, 9 perceived risk questions, and 1 measure of altruistic acceptance of risk. The 9 COVID-19 risk questions and 1 altruism question were adapted from 2 previous studies that assessed perceived risk of developing and transmitting hospital employees in Taiwan and China. ${ }^{2}$ The perception of risk and stress were assessed on a 5-point Likert scale (strongly disagree; disagree; neutral; agree; strongly agree). The electronic survey tool was pilot tested with 2 attending physicians, 2 resident physicians, and 2 nurses to ensure local context applicability and feasibility. Questions were modified based on their feedback. This survey had an acceptable internal consistency, with a Cronbach's $\alpha$ of 0.72 .

\section{Data Analysis}

For this study, we selected responses from medical staff, including physicians, registered nurses, nurse practitioners, and physician assistants. We divided subjects into 2 discrete groups based on exposure to patients: registered nurses, who theoretically have more bedside exposure to patients, ${ }^{8}$ and medical providers, which include physicians (attending and trainee) and advanced practice providers (nurse practitioners and physician assistants). In our institution, advanced practice providers operate in the same way as residents. The survey results were dichotomized to compare responses of strongly disagree, disagree, and neutral, to agree and strongly agree. We used the $\chi^{2}$ test to compare the responses of medical providers and nurses on all the survey questions. We also used a multivariable logistic regression model to compare the differences in odds of having thoughts about resigning between nurses and medical providers while controlling for demographic and COVID-related variables. Analyses were conducted in STATA 14 (StataCorp, College Station, TX). We considered $P$ values less than 0.05 to be significant.

\section{Results}

We received 445 medical staff and nurse responses to our survey. 43 of the surveys were excluded due to missing responses. There were no significant differences in demographic or perceived risk variables for the included and excluded groups. Missing data analysis is provided in supplemental appendix.

In Table 1, we describe the demographic characteristics, occupational characteristics, and COVID19 exposure of respondents to the survey. The demographic characteristics of the nurses significantly differed from that of the medical providers. 
Nurses were more likely to be female. A greater percentage of them identified as black, and a greater percentage of them also reported being over 50 years of age. There were no significant differences between the nurses and medical providers in the percentages of those who cared for COVID-19 patients, had family members or friends with COVID-19, or were in quarantine for COVID-19 diagnosis or exposure.

In Table 2, we show various factors that contribute to stress in health care workers during the
COVID-19 pandemic. Within these categories, more medical providers were more likely to agree or strongly agree that their job is putting them at risk $(75.0 \%$ vs $67.0 \%, P<.05)$ and that they are concerned about passing COVID to others $(89.1 \%$ vs $81.6 \%, P=.04)$. Categories that nurses were more likely to agree or strongly agree with were that they may not survive if they get COVID (13.3\% vs 3.3\%, $P<.001)$, are having thoughts of resigning $(21.6 \%$ vs $6.0 \%, P<.001)$, and people are avoiding their family because of their jobs $(40.4 \%$ vs $25.0 \%, P=.001)$.

Table 1. Demographic Characteristics, Occupational Chracteristics, and CoVID-19 Exposure of Responders

\begin{tabular}{|c|c|c|c|c|}
\hline Categories & $\begin{array}{c}\text { Total } \\
(\mathrm{n}=402) \\
\mathrm{N}(\%)\end{array}$ & $\begin{array}{c}\text { Medical } \\
\text { Providers } \\
(\mathrm{n}=184) \\
\mathrm{N}(\%)\end{array}$ & $\begin{array}{c}\text { Registered } \\
\text { Nurses } \\
(\mathrm{n}=218) \\
\mathrm{N}(\%)\end{array}$ & $P$ Value \\
\hline \multicolumn{5}{|l|}{ Sex } \\
\hline Female & $308(76.6 \%)$ & $110(59.8 \%)$ & $198(90.8 \%)$ & \multirow[t]{2}{*}{$<.001$} \\
\hline Male & $94(23.4 \%)$ & $74(40.2 \%)$ & $20(9.2 \%)$ & \\
\hline \multicolumn{5}{|l|}{ Age, y } \\
\hline$<30$ & $115(28.6 \%)$ & $59(32.1 \%)$ & $56(25.7 \%)$ & \multirow[t]{5}{*}{$<.001$} \\
\hline 30 to 39 & $173(43.0 \%)$ & $89(48.4 \%)$ & $84(38.5 \%)$ & \\
\hline 40 to 49 & $54(13.4 \%)$ & $24(13.0 \%)$ & $30(13.8 \%)$ & \\
\hline 50 to 59 & $34(8.5 \%)$ & $9(4.9 \%)$ & $25(11.5 \%)$ & \\
\hline$>59$ & $26(6.5 \%)$ & $3(1.6 \%)$ & $23(10.5 \%)$ & \\
\hline \multicolumn{5}{|l|}{ Ethnicity } \\
\hline White, non-Hispanic & $236(58.7 \%)$ & $116(63.0 \%)$ & $120(50.0 \%)$ & \multirow[t]{5}{*}{$<.001$} \\
\hline Black, non-Hispanic & $53(13.2 \%)$ & $8(4.4 \%)$ & $45(20.6 \%)$ & \\
\hline Hispanic & $14(3.5 \%)$ & $6(3.3 \%)$ & $8(3.7 \%)$ & \\
\hline Asian & $63(15.7 \%)$ & $38(20.6 \%)$ & $25(11.5 \%)$ & \\
\hline Other & $36(9.0 \%)$ & $16(8.7 \%)$ & $20(9.2 \%)$ & \\
\hline \multicolumn{5}{|l|}{ Specialty } \\
\hline Emergency department & $44(11.0 \%)$ & $12(6.5 \%)$ & $32(14.7 \%)$ & \multirow[t]{8}{*}{$<.001$} \\
\hline Intensive care unit & $61(15.2 \%)$ & $29(15.8 \%)$ & $32(14.7 \%)$ & \\
\hline Perioperative & $32(8.0 \%)$ & $8(4.4 \%)$ & $24(11.0 \%)$ & \\
\hline Surgery & $52(12.9 \%)$ & $28(15.2 \%)$ & $24(11.0 \%)$ & \\
\hline Medicine & $70(17.4 \%)$ & $45(24.5 \%)$ & $25(11.5 \%)$ & \\
\hline Psychiatry & $11(2.7 \%)$ & $7(3.8 \%)$ & $4(1.8 \%)$ & \\
\hline Women's services & $50(12.4 \%)$ & $13(7.1 \%)$ & $37(17.0 \%)$ & \\
\hline Other & $82(20.4 \%)$ & $42(22.8 \%)$ & $40(18.4 \%)$ & \\
\hline $\begin{array}{l}\text { Parent or primary caregiver for a } \\
\text { school age child or younger }\end{array}$ & $106(26.4 \%)$ & $44(23.9 \%)$ & $62(28.4 \%)$ & .31 \\
\hline $\begin{array}{l}\text { Primary caregiver or live with } \\
\text { someone }>80 \text { years old }\end{array}$ & $6(1.4 \%)$ & $0(0.0 \%)$ & $6(2.8 \%)$ & .02 \\
\hline $\begin{array}{l}\text { Cared for a patient with diagnosed or } \\
\text { suspected COVID-19 }\end{array}$ & $265(65.9 \%)$ & $127(69.0 \%)$ & $138(63.3 \%)$ & .23 \\
\hline $\begin{array}{l}\text { Has a friend/close relative who } \\
\text { contracted COVID-19 }\end{array}$ & $149(37.0 \%)$ & $68(37.0 \%)$ & $81(37.2 \%)$ & .97 \\
\hline $\begin{array}{l}\text { Has been in quarantine for potential } \\
\text { COVID-19 exposure }\end{array}$ & $51(12.7 \%)$ & $22(12.0 \%)$ & $29(13.3 \%)$ & .69 \\
\hline
\end{tabular}

Although both clinical and non-clinical staff were surveyed, only responses from medical providers (attending physicians, residents, nurse practitioners and physician assistants) and registered nurses were included in analysis. 
Table 2. Stress Factors of Medical Providers Compared to Registered Nurses

\begin{tabular}{|c|c|c|c|c|}
\hline Category & $\begin{array}{l}\text { All Responses } \\
\qquad(\mathrm{n}=402) \\
\mathrm{N}(\%)\end{array}$ & $\begin{array}{l}\text { Medical Providers } \\
(\mathrm{n}=184) \\
\mathrm{N}(\%)\end{array}$ & $\begin{array}{l}\text { Registered Nurses } \\
(\mathrm{n}=218) \\
\mathrm{N}(\%)\end{array}$ & $P$ Value \\
\hline My job is putting me at great risk. & $284(70.6 \%)$ & $138(75.0 \%)$ & $146(67.0 \%)$ & .08 \\
\hline I feel extra stress at work. & $318(79.1 \%)$ & $142(77.2 \%)$ & $176(80.7 \%)$ & .38 \\
\hline I am afraid of falling ill with COVID-19. & $290(72.1 \%)$ & $132(71.7 \%)$ & $158(72.5 \%)$ & .87 \\
\hline $\begin{array}{l}\text { I have little control over whether I get } \\
\text { infected or not. }\end{array}$ & $227(56.5 \%)$ & $109(59.2 \%)$ & $118(54.2 \%)$ & .30 \\
\hline $\begin{array}{l}\text { I am unlikely to survive if I were to get } \\
\text { COVID-19. }\end{array}$ & $35(8.7 \%)$ & $6(3.3 \%)$ & $29(13.3 \%)$ & $<.001$ \\
\hline $\begin{array}{l}\text { I think about resigning because of } \\
\text { COVID-19. }\end{array}$ & $58(14.4 \%)$ & $11(6.0 \%)$ & $47(21.6 \%)$ & $<.001$ \\
\hline $\begin{array}{l}\text { I am afraid I will pass COVID-19 on to } \\
\text { others. }\end{array}$ & $342(95.1 \%)$ & $164(89.1 \%)$ & $178(81.6 \%)$ & .04 \\
\hline $\begin{array}{l}\text { My family and friends are worried they } \\
\text { might get infected through me. }\end{array}$ & $264(65.7 \%)$ & $117(63.6 \%)$ & $147(67.4 \%)$ & .51 \\
\hline $\begin{array}{l}\text { People avoid my family because of my } \\
\text { work. }\end{array}$ & $134(33.3 \%)$ & $46(25.0 \%)$ & $88(40.4 \%)$ & .001 \\
\hline $\begin{array}{l}\text { Altruism: Because I want to help the } \\
\text { COVID-19 patients, I am willing to } \\
\text { accept the risks involved. }\end{array}$ & $267(63.4 \%)$ & $147(79.9 \%)$ & $120(55.0 \%)$ & $<.001$ \\
\hline
\end{tabular}

Survey responses were dichotomized to include "agreed" or "strongly agreed" as positive responses. This table shows the frequency of positive responses for each category while also comparing the differences in responses between medical providers and nurses.

In Table 3, we present the results of the multivariable logistic regression model exploring the difference in thoughts about resigning due to COVID-19. After controlling for other demographic and COVID-related characteristics, nurses had 3.87 times the odds of considering resignation due to COVID-19 than medical providers. In addition, health care workers who had a friend or close relative who contracted COVID-19 had 55\% lower odds than those who did not. Health care workers who had been in quarantine for potential COVID19 exposure had 68\% lower odds of considering resignation than those who had not.

Figure 1 displays the levels of altruism of health care workers during the COVID-19 pandemic based on their occupation. $77.4 \%$ of medical providers (80.5\% of attending physicians, $74.1 \%$ of resident physicians, $82.6 \%$ of advanced practitioners), and $55.0 \%$ of nurses strongly agreed or agreed with the statement, "because I want to help the COVID-19 patients, I am willing to accept the risks." These trends were consistent after controlling for covariates in logistic regression presented as predicted probabilities (see Supplemental Table 1).

\section{Discussion}

Our cross-sectional survey revealed that transmission risk, extra stress at work, and risk to self were great sources of distress to medical staff during the pandemic. Our study also found a higher percentage of nurses considering resignation due to COVID-19 when compared with medical providers, but the altruism scores were high in both groups overall.

As health care workers face a unique set of stressors posed by COVID-19, concerns about its impact on the stress levels and mental health of these workers are arising. Several recently published studies address this topic; however, they were all conducted on health care workers in China. Various factors including politics, culture, and infrastructure of the health care system of a region may influence their working environment, and therefore their experiences and reactions to this crisis. This demonstrates the need to implement similar studies in the current epicenter of the pandemic (United States) to better prepare health care workers in response to a disaster.

Several previous studies demonstrated a correlation between perceived safety and risk and the physical and psychological wellbeing of health care workers. For example, higher levels of trust in hospital equipment and infection control measures predicted lower levels of emotional exhaustion and state anger in nurses. ${ }^{9}$ Perception of personal risk from a disease outbreak was associated with posttraumatic stress symptoms. ${ }^{4}$ On the other hand, 
Table 3. Multivariable Linear Regression Model Regressing for Thoughts about Resigning Due to COVID-19 Based on Occupation

\begin{tabular}{|c|c|c|c|}
\hline Categories (reference group) & Odds Ratio (SE) & $95 \%$ CI & $P$ Value \\
\hline \multicolumn{4}{|l|}{ Occupation (Reference: Medical providers) } \\
\hline Nurse & $3.87(1.63)$ & $1.69,8.84$ & .001 \\
\hline \multicolumn{4}{|l|}{ Age, y (Reference: <30) } \\
\hline 30 to 39 & $1.12(0.48)$ & $0.48,2.59$ & .80 \\
\hline 40 to 49 & $0.34(0.22)$ & $0.09,1.21$ & .10 \\
\hline 50 to 59 & $0.88(0.57)$ & $0.25,3.13$ & .85 \\
\hline$>60$ & $2.30(1.41)$ & $0.69,7.68$ & .18 \\
\hline \multicolumn{4}{|l|}{ Gender (Reference: Male) } \\
\hline Female & $1.47(0.77)$ & $0.53,4.09$ & .46 \\
\hline \multicolumn{4}{|l|}{ Race (Reference: White, non-Hispanic) } \\
\hline Black, non-Hispanic & $0.76(0.40)$ & $0.27,2.13$ & .60 \\
\hline Hispanic & $4.86(3.58)$ & $1.15,20.62$ & .032 \\
\hline Asian & $1.49(0.71)$ & $0.58,3.81$ & .41 \\
\hline Other & $1.77(0.89)$ & $0.66,4.72$ & .26 \\
\hline \multicolumn{4}{|l|}{ Specialty (Reference: Emergency department) } \\
\hline Intensive care unit & $2.14(1.38)$ & $0.61,7.58$ & .24 \\
\hline Perioperative & $2.78(2.10)$ & $0.63,12.24$ & .18 \\
\hline Surgery & $0.78(0.64)$ & $0.15,3.93$ & .76 \\
\hline Medicine & $1.88(1.31)$ & $0.48,7.34$ & .36 \\
\hline Psychiatry & $0.83(1.11)$ & $0.06,11.33$ & .89 \\
\hline Women's services & $2.31(1.59)$ & $0.60,8.89$ & .22 \\
\hline Other & $1.78(1.16)$ & $0.50,6.36$ & .37 \\
\hline Parent or primary caregiver for a school age child or younger & $0.55(0.21)$ & $0.26,1.15$ & .11 \\
\hline Primary caregiver or live with someone $>80$ years old & $0.34(0.35)$ & $0.05,2.49$ & 0.29 \\
\hline Cared for a patient with diagnosed or suspected COVID-19 & $1.35(0.52)$ & $0.63,2.88$ & 0.44 \\
\hline Has a friend/close relative who contracted COVID-19 & $0.45(0.15)$ & $0.23,0.85$ & 0.015 \\
\hline Has been in quarantine for potential COVID-19 exposure & $0.32(0.13)$ & $0.14,0.73$ & 0.006 \\
\hline Constant & $1.37(2.44)$ & $0.04,45.48$ & 0.86 \\
\hline
\end{tabular}

SE, standard error; CI, confidence interval.

After controlling for demographic and COVID-related characteristics, analysis showed that nursing staff had greater odds of considering resignation, those who had a friend or close relative who contracted COVID-19 and those who had been in quarantine had lower odds of considering resignation with a Pseudo $\mathrm{R}^{2}$ of 0.1809 .

altruistic acceptance of job-related risk showed protective effects on psychological wellbeing. ${ }^{4}$ Improving our understanding of these perceived risks and threats can help design interventions to reduce the amount of risk felt by the employees, promote environments conducive to altruism, and thus lead to a positive impact on the wellbeing of health care workers.

Categories with the highest percentage of medical providers who "agreed" or "strongly agreed" included fear of passing disease onto others (Transmission), feeling of extra stress at work (Stress), and perception of great risk at one's job (Risk). Categories with the highest number of nurses who "agreed" or "strongly agreed" were Transmission, Stress, Risk, and Family (having family and friends worrying they might get infected through the health care worker). Considering the highly contagious nature of COVID-19, it is not surprising that both medical providers and nurses considered the risk of transmission to be one of the most significant sources of distress. In addition, the limited supply of personal protective equipment (PPE) for health care personnel may be an explanation to why the majority of medical staff agreed or strongly agreed that their job is putting them at great risk. As a caveat, our hospital did have more PPE than most but a 1-mask per day policy was utilized in the early stages of the pandemic to conserve in case of a surge or supply chain issues. As the magnitude and spread of COVID-19 are becoming ever more apparent with unprecedented equipment 
Figure 1. Levels of altruism of health care workers during COVID-19 pandemic based on occupation.

Responses to the altruism statement: "Because I want to help

the COVID-19 patients, I am willing to accept the risks" was

further broken down by specific occupation of health care workers

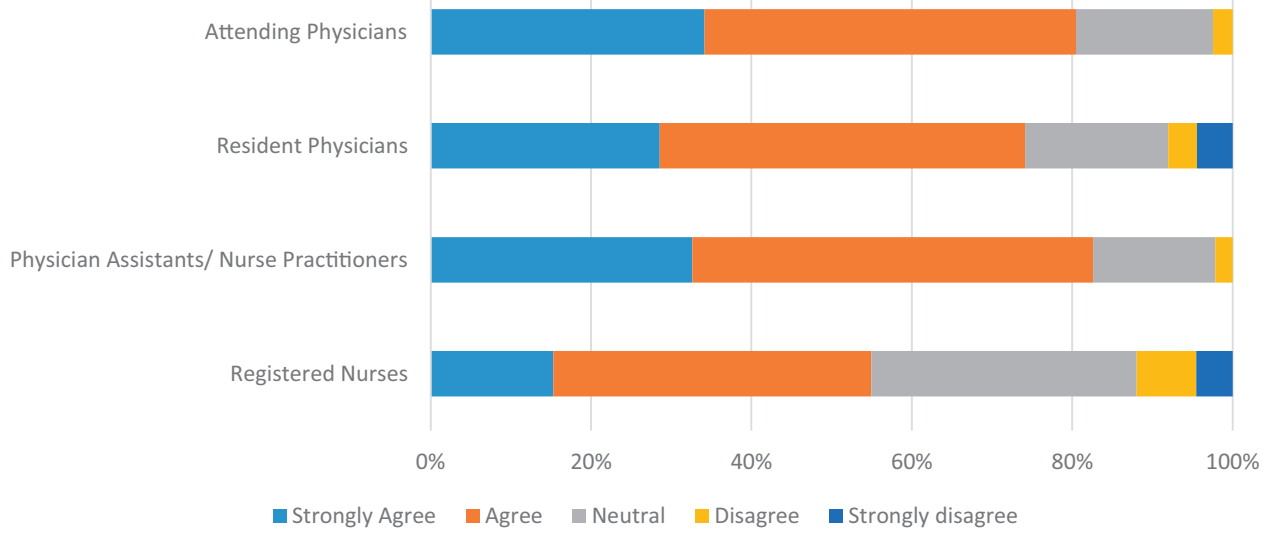

shortages and overwhelmed intensive care systems, health care workers confront ethical dilemmas regarding the allocation of these limited and frequently life-saving resources to equally needy patients. ${ }^{10-12}$ In addition, nonemergency department and non-intensive care unit physicians and nurses were asked to step into roles in the emergency department or intensive care unit. Thus, these health care workers encounter a predicament about providing care outside of one's scope of practice. ${ }^{10}$ All these elements may be responsible for the high percentage of medical staff who agreed or strongly agreed that they feel extra stress at work.

Our results complement the findings from a recent study from China during the COVID-19 pandemic, which found the medical staff's primary concerns to be the lack of PPE, lack of sleep, contagion risks to their family members, inability to handle patients unwilling to quarantine or cooperate, and feelings of inadequacy treating critically ill patients. ${ }^{13}$ Studies during the SARS-CoV-1 outbreak of 2003 showed similar findings, with major contributors to distress in health care workers being fear of contracting the disease, fear of spreading the infection to loved ones, treating colleagues with SARS, and interpersonal isolation. ${ }^{14-18}$

A significantly higher percentage of medical providers than nurses agreed or strongly agreed with statements in the Risk and Transmission categories. This is a surprising finding considering nurses have closer and more frequent contact with patients, which initially led us to predict that nurses would have a greater perceived risk of contracting and spreading COVID-19 than medical providers. On the other hand, a significantly higher percentage of nurses than medical providers agreed or strongly agreed with statements in the Survival ("I am unlikely to survive if I were to get COVID-19") and Social ("People avoid my family because of my work") categories. This may reflect the differences in demographic patterns of nurses in our institution. Nurses were more likely to be African American and over 50 years of age. Both groups have been found to have high rates of severe COVID-19 illness, which may influence the risks that they perceive that they are under and subsequently lead to increased post-traumatic stress. ${ }^{19,20}$ These findings are in accordance with a cross-sectional, survey-based study on health care workers in Wuhan, China that reported significantly higher levels of distress and mental health symptoms in nurses compared with other health care workers. ${ }^{1}$

Nurses have reported experiencing more severe symptoms of depression, anxiety, insomnia, and distress than doctors in China during the height of the COVID-19 pandemic. ${ }^{1}$ A possible explanation for this finding may be that nurses have close and frequent contact with patients, exposing them to the highest risk of infection. ${ }^{8}$ More alarming are the results of a study conducted following during the SARS-CoV-1 outbreak in Toronto, which showed that nurses and other hospital staff that cared for SARS patients had a significant decline in their time at the bedside, decreased face-to-face 
contact with patients, and decreased total work hours even after the outbreak's resolution. ${ }^{3}$

It is concerning that nurses have significantly greater odds of considering resignation because of COVID-19 than medical providers. Heightened anxiety about falling ill with COVID-19 and experiences of social isolation may be correlated to their stronger considerations to resignation. Turnover in the nursing profession is already very high. Annual nursing turnover rates are estimated to be at $27 \% .^{21}$ These results are alarming as high rates of nursing turnover will likely be highly disruptive to hospitals during a pandemic as hospitals may also be dealing with frequent absenteeism due to COVID-19 exposures. Research is urgently needed to identify strategies to minimize nursing turnover during the pandemic.

We selected resigning as the outcome measure of interest for the regression model as it bears a significant impact on our health care system. While we recognize that thoughts of resigning may vary from day to day, we believe that it provides a general approximation of the accumulated stresses and risks borne by health care workers. Interestingly, factors associated with fewer thoughts of resignation due to COVID-19 include having a close friend/relative who contracted COVID-19 and having been in quarantine for potential COVID-19 exposure. A study during the Middle East Respiratory Syndrome (MERS) outbreak revealed that treating one's own colleagues sick from MERS was a top factor causing stress in health care workers. ${ }^{22}$ However, no past study to our knowledge has associated this with thoughts of resignation. One can only speculate about the reasons for our findings. Perhaps, witnessing a loved one suffer from COVID-19 reinforced health care workers' sense of duty and altruism. With physical exhaustion and sleep deprivation established as some of the greatest sources of distress during disease outbreaks, ${ }^{14,22}$ enforced quarantine may have provided the muchneeded break and rest for the overworked health care workers.

When comparing responses from the altruism category, significantly greater percentage of medical staff members than nurses agreed or strongly agreed to "because I want to help the COVID-19 patients, I am willing to accept the risks involved." Several explanations could account for this unexpected finding. First, as mentioned previously, nurses are at higher risk of acquiring COVID-19 due to their frequent contact with patients. Higher risks are naturally more difficult to accept. Second, nurses experience more severe mental health symptoms during disease outbreaks as described in several studies. ${ }^{1,23}$ Is it possible that these mental health symptoms leave less mental capacity for altruism? This topic warrants additional investigation. Although the difference between medical providers and nurses was statistically significant, it is reassuring to observe that the majority of all health care workers, regardless of position, showed high levels of altruism.

This study has several limitations. It is limited in scope as it is a single-center study. As it is a crosssectional survey study, no causal relationships can be concluded between perceived risk factors and the levels of altruism or thoughts of resignation. We did not receive sufficient survey response to examine each of the positions included in the study separately, but we identify that each of these positions has unique challenges and experiences. For instance, our COVID-19 intensive care unit was only staffed by advanced practice providers. Residents and fellows worked on the other intensive care units during the height of the pandemic.

At the time that we designed this survey, there was no survey tool available to understand the perceived risks of COVID-19 to health care workers. COVID-19 specific validated tools have subsequently been developed. ${ }^{24}$ Hence, we modified survey questions utilized by Chong and $\mathrm{Wu}$ in their study of the impact of the SARS epidemic on health care workers. ${ }^{2,4}$

The data used to conduct this analysis is part of a larger project where we are aiming to track the impact of COVID-19 on health care workers longitudinally. Due to this design, it is possible for respondents to be represented more than once, which makes the true response rate difficult to fathom, as has the potential to bias the findings. We also did not include a question about how much time the provider spent with COVID-19 patients. Certainly, the perceived risks of a nurse working every day in the COVID-19 ICU would be very different from a nurse working in labor and delivery who would only occasionally care for a laboring woman with COVID-19. Lastly, response bias may exist because nonrespondents could have been either too stressed to respond or not at all stressed and therefore not interested in taking the survey. 
In the future, we intend to complete the longitudinal study to chart changes in perceived risk levels among health care providers in response to both local and national changes and to use these findings to identify interventions that positively affect the mental wellbeing of our staff.

\section{Conclusion}

In this survey study of health care workers in a hospital with COVID-19 positive patients in Washington, DC, transmission risk, extra stress at work, and risk to self were the great sources of distress to medical staff during the pandemic. A higher percentage of nurses considered resignation due to COVID-19 when compared with medical providers, but the levels of altruism were high in both groups overall. It is essential to develop and implement interventions to preserve the well-being of health care workers during this pandemic, with special attention to the nurses.

To see this article online, please go to: http://jabfm.org/content/ 34/Supplement/S103.full.

\section{References}

1. Lai J, Ma S, Wang Y, et al. Factors associated with mental health outcomes among health care workers exposed to coronavirus disease 2019. JAMA Netw Open 2020;3:e203976.

2. Chong M-Y, Wang W-C, Hsieh W-C, et al. Psychological impact of severe acute respiratory syndrome on health workers in a tertiary hospital. Br J Psychiatry 2004;185:127-33.

3. Maunder RG, Leszcz M, Savage D, et al. Applying the lessons of SARS to pandemic influenza: an evidence-based approach to mitigating the stress experienced by healthcare workers. Can J Public Health 2008;99:486-8.

4. Wu P, Fang Y, Guan Z, et al. The psychological impact of the SARS epidemic on hospital employees in China: exposure, risk perception, and altruistic acceptance of risk. Can J Psychiatry 2009; 54:302-11.

5. Wang H, Liu Y, Hu K, et al. Healthcare workers' stress when caring for COVID-19 patients: An altruistic perspective. Nurs Ethics 2020;27:1490-500.

6. Smith R, Lagarde M, Blaauw D, et al. Appealing to altruism: an alternative strategy to address the health workforce crisis in developing countries? J Public Health (Oxf) 2013;35:164-70.

7. Ko NY, Feng MC, Chiu DY, et al. Applying theory of planned behavior to predict nurses' intention and volunteering to care for SARS patients in southern Taiwan. Kaohsiung J Med Sci 2004;20:389-98.
8. Leppin A, Aro AR. Risk perceptions related to SARS and avian influenza: theoretical foundations of current empirical research. Int J Behav Med 2009;16:7-29.

9. Marjanovic Z, Greenglass ER, Coffey S. The relevance of psychosocial variables and working conditions in predicting nurses' coping strategies during the SARS crisis: An online questionnaire survey. Int J Nurs Stud 2007;44:991-8.

10. Bansal P, Bingemann TA, Greenhawt $M$, et al. Clinician wellness during the COVID-19 pandemic: extraordinary times and unusual challenges for the allergist/immunologist. J Allergy Clin Immunol Pract 2020;8:1781-90.e3.

11. Albott CS, Wozniak JR, McGlinch BP, Wall MH, Gold BS, Vinogradov S. Battle buddies: rapid deployment of a psychological resilience intervention for health care workers during the COVID-19 pandemic. Anesth Analg 2020;131: 43-54.

12. Greenberg N, Docherty M, Gnanapragasam S, Wessely S. Managing mental health challenges faced by healthcare workers during covid-19 pandemic. BMJ 2020;386:m1211. doi: 10.1136/bmj.m1211.

13. Chen Q, Liang M, Li Y, et al. Mental health care for medical staff in China during the COVID-19 outbreak. Lancet Psychiatry 2020;7:e15-e16.

14. Maunder R, Hunter J, Vincent L, et al. The immediate psychological and occupational impact of the 2003 SARS outbreak in a teaching hospital. CMAJ 2003;168:1245-51.

15. Bai Y, Lin C-C, Lin C-Y, Chen J-Y, Chue C-M, Chou P. Survey of stress reactions among health care workers involved with the SARS outbreak. Psychiatr Serv 2004;55:1055-7.

16. Chua SE, Cheung V, Cheung $\mathrm{C}$, et al. Psychological effects of the SARS outbreak in Hong Kong on high-risk health care workers. Can J Psychiatry 2004;49:391-3.

17. Lin C-Y, Peng Y-C, Wu Y-H, Chang J, Chan C$\mathrm{H}$, Yang D-Y. The psychological effect of severe acute respiratory syndrome on emergency department staff. Emerg Med J 2007;24:12-7.

18. Tam CWC, Pang EPF, Lam LCW, Chiu HFK. Severe acute respiratory syndrome (SARS) in Hong Kong in 2003: stress and psychological impact among frontline healthcare workers. Psychol Med 2004;34:1197-204.

19. Garnier-Crussard A, Forestier E, Gilbert T, Krolak-Salmon P. Novel coronavirus (COVID-19) epidemic: what are the risks for older patients? J Am Geriatr Soc 2020;68:939-40.

20. Killerby ME, Link-Gelles R, Haight SC, CDC COVID-19 Response Clinical Team, et al. Characteristics associated with hospitalization among patients with COVID-19 - Metropolitan Atlanta, Georgia, March-April 2020. MMWR Morb Mortal Wkly Rep 2020;69:790-4. 
21. Duffield CM, Roche MA, Homer C, Buchan J, Dimitrelis S. A comparative review of nurse turnover rates and costs across countries. J Adv Nurs 2014;70:2703-12.

22. Khalid I, Khalid TJ, Qabajah MR, Barnard AG, Qushmaq IA. Healthcare workers emotions, perceived stressors and coping strategies during a MERS-CoV outbreak. Clin Med Res 2016;14: 7-14.
23. Mok E, Chung BP, Chung JW, Wong TK. An exploratory study of nurses suffering from severe acute respiratory syndrome (SARS). Int J Nurs Pract 2005;11:150-60.

24. Talaee N, Varahram M, Jamaati H, et al. Stress and burnout in health care workers during COVID-19 pandemic: validation of a questionnaire. Z Gesundh Wiss 2020;1-6. doi: 10.1007/ s10389-020-01313-z. 


\section{APPENDIX}

\section{Appendix 1. Survey Questions: Survey Questions for COVID-19 Exposure and Stress Factors}

Please Respond to the Following Set of Questions by Responding Yes or No

Are you a parent or primary caregiver for school-aged child or younger

Are you a primary caregiver for or lives with a person over age of 80

Have you cared for a patient with diagnosed or suspected COVID-19?

Do you have any friends/close relative that have contracted COVID-19?

Have you been in quarantine for a potential exposure to COVID-19?

Please Select How Much You Agree or Disagree with the Following Statements

\begin{tabular}{l}
\hline \\
My job is putting me at great risk. \\
I feel extra stress at work. \\
I am afraid of falling ill with COVID-19. \\
I have little control over whether I get \\
infected or not. \\
I am unlikely to survive if I were to get \\
COVID-19. \\
I think about resigning because of \\
COVID-19. \\
I am afraid I will pass COVID-19 on to \\
others. \\
My family and friends are worried they \\
might get infected through me. \\
People avoid my family because of my \\
work \\
Because I want to help the COVID-19 \\
patients, I am willing to accept the \\
risks involved.
\end{tabular}

